\title{
A three dimensional model of the photosynthetic membranes of Ectothiorhodospira halochloris
}

\author{
G. Wanner, R. Steiner, and H. Scheer \\ Botanisches Institut der Universität München, Menzinger Str. 67, D-8000 München 19, Federal Republic of Germany
}

\begin{abstract}
The three dimensional organization of the complete photosynthetic apparatus of the extremely halophilic, bacteriochlorophyll $b$ containing Ectothiorhodospira halochloris has been elaborated by several techniques of electron microscopy. Essentially all thylakoidal sacs are disc shaped and connected to the cytoplasmic membrane by small membraneous "bridges". In sum, the lumina of all thylakoids (intrathylakoidal space) form one common periplasmic space. Thin sections confirm a paracrystalline arrangement of the photosynthetic complexes in situ. The ontogenic development of the photosynthetic apparatus is discussed based on a structural model derived from serial thin sections.
\end{abstract}

Key words: Photosynthesis - Membrane structure Electron microscopy - Ectothiorhodospira - Serial thin sectioning - Three dimensional reconstruction

Ectothiorhodospira halochloris is one of the few photosynthetic bacteria containing bchl $b$ (Drews and Giesbrecht 1966; Eimhjellen et al. 1963; Neutzling and Trüper 1982; Eimhjellen 1970; Imhoff and Trüper 1981). Electron micrographs of negatively stained cells show that intracytoplasmic stacks of thylakoidal sacs are the dominant internal structures (Imhoff and Trüper 1977). Detailed structural investigations of isolated photosynthetic membranes of E.halochloris led to almost molecular resolution of the three dimensional structure of the hexagonally packed photosynthetic complexes (Engelhardt et al. 1983). Besides this, no other data about the in situ arrangement of the membranes are available. One reason may be that it is very difficult to get adequate preparations of extremely halophilic organisms, which are osmotically very sensitive (Raymond and Sistrom 1967). However, a complete three dimensional reconstruction of the photosynthetic apparatus is necessary, not only for discussion of ontogenetic aspects but also for a better understanding of photosynthesis in bacteria. This is in particular important regarding details of Mitchell's chemiosmotic hypothesis and comparison to photosynthesis in procaryotes. It is a fundamental difference whether the thylakoids develop as invaginations from the cytoplasmic membrane and are finally pinched off ("closed system"), or

Offprint requests to: $\mathrm{H}$. Scheer

Abbreviations. E., Ectothiorhodospira; bchl, bacteriochlorophyll; $R .$, Rhodopseudomonas; $\mathrm{RC}$, reaction center are permanently in continuity with the cytoplasmic membrane ("open system"), as discussed by Remsen et al. (1968).

Here we report several new observations concerning the organisation of the photosynthetic apparatus of E.halochloris within the intact cells. For this purpose we applied isoosmotic fixation, thin sectioning and serial sectioning techniques for three dimensional reconstruction, and morphometry for quantification and comparison of structural parameters with biochemical data (Steiner and Scheer 1985; Steiner 1985).

\section{Material and methods \\ Organism and culture conditions}

Stock cultures of Ectothiorhodospira (E.) halochloris (DSM 1059) were kindly provided by Dr. J. F. Imhoff, Bonn. E.halochloris was cultivated anaerobically by transferring 1.51 of exponentially growing bacteria in 13.51 freshly prepared saline medium in 151 flasks at $35^{\circ} \mathrm{C}$. The basal medium of Imhoff and Trüper (1977) was modified by removal of sodium sulfate and the vitamin solution. The organisms were grown under constant illumination with 1700 lux (at the surface of the culture) and agitated gently with a magnetic stirrer for homogenous distribution. The cells were harvested 20 days after inoculation by centrifugation (30 min at $10,000 \times g$ ). Protein concentration was determined by the Coomassie Brillant Blue technique (Bio-Rad method).

Bacteriochlorophyll $b$ (Bchl $b$ ) was quantitatively extracted by the method of Strain and Svec (1966), paying attention, that the samples were kept in the dark to inhibit any photoreaction (Steiner et al. 1983). Extinction coefficients were determined after the light induced conversion of bchl $b$ to 3-devinyl-3-acetylchlorophyll $a$ under strictly unaerobic conditions as described in detail (Steiner et al. 1983) and compared to those described for bchl $a$ (Sauer et al. 1966; Gottstein 1984). Absorption spectra were recorded either on a spectrophotometer DMR 22 (Zeiss, Oberkochen, FRG) or a PE320 (Perkin Elmer, Überlingen, FRG).

\section{Electron microscopy and morphometry}

Freshly harvested cells were fixed for $120 \mathrm{~min}$ at room temperature with $3 \%$ glutardialdehyde in fixative buffer

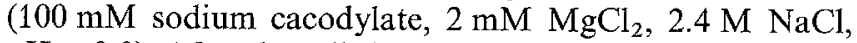
$\mathrm{pH}=9.0$ ). After the cells had been rinsed several times with the same buffer, they were postfixed for $2 \mathrm{~h}$ in $2 \%$ osmium 
tetraoxide in fixative buffer. The fixed cells were dehydrated in acetone/saline buffer $(2.4 \mathrm{M} \mathrm{NaCl})$ in the following steps:

$\begin{array}{rl}\text { acetone concentration } & \text { final NaCl concentration } \\ 0 \% & 2.4 \mathrm{M} \\ 20 \% & 1.9 \mathrm{M} \\ 40 \% & 1.44 \mathrm{M} \\ 40 \% & 0.72 \mathrm{M} \\ 40 \% & 0.36 \mathrm{M} \\ 40 \% & 0.18 \mathrm{M} \\ 40 \% & - \\ 60 \% & - \\ 80 \% & - \\ 100 \% & -\end{array}$

For enbloc staining the cells were incubated with $1 \%$ uranyl magnesium acetate in $20 \%$ acetone $/ 80 \%$ buffer for $60 \mathrm{~min}$. They were infiltrated and embedded in Spurr's low viscosity resin (Spurr 1969). Thin layers of resin-infiltrated cells were polymerized on glass slides for light microscopy and documentation. Silvergrey and grey sections were cut with a diamond knife on a LKB Ultrotome II and mounted either on uncoated or Formvar-coated copper grids. The sections were poststained with aqueous lead citrate $(3 \%, \mathrm{pH}=13.0)$. All pictures were taken with a Elmiskop 101 (Siemens) electron microscope. Morphometric measurements were made with a semi-automated measuring device (Kontron MOP AM02).

\section{Negative staining}

For negative staining, suspensions of whole cells or isolated chromatophores were used directly or after stabilization with $1 \%$ glutardialdehyde in $25 \mathrm{mM}$ tricine buffer $(\mathrm{pH}=$ 7.0). Drops of the suspension were placed either on carboncoated copper grids or on graphite oxide-covered holey carbon films as described by Formanek (1979). Negative staining was achieved with $1 \%$ potassium phosphotungstate $(\mathrm{pH}=6.8)$.

\section{Results}

\section{Ultrastructural observations}

As described in detail by Imhoff and Trüper (1977), cells of Ectothiorhodospira halochloris appear bipolary flagellated, spiral shaped with a length ranging from 2.5 to $8.0 \mu \mathrm{m}$ and a diameter of about $0.5 \mu \mathrm{m}$. Under our culture conditions of exponential growth, the cells were about $4.0 \mu \mathrm{m}$ long and immobile when observed by phase contrast microscopy. Negative staining of whole $E$. halochloris cells confirmed that the cells were not flagellated. It seems to be a significant feature for E. halochloris that many cellular parameters like size, shape or flagellation depend on cultural and/or environmental conditions. The examination of cells directly sedimented on coated copper grids and then negatively stained was found to be difficult due to deposits of sulfur at the cell surface and to crystallization of $\mathrm{NaCl}$. Washing of the cells in order to remove excess salt and sulfur resulted on one hand in a better resolution, but on the other it caused swelling and bursting. In this case the "stacks" of photosynthetic membranes formed rows of overlapping discs (Fig. 1).

Thin sectioning of whole cells confirmed the regular array of thylakoidal membranes (Fig. 2). The architecture
Table 1. Cellular parameters of Ectothiorhodospira halochloris under cultural conditions as described in Material and methods

\begin{tabular}{|c|c|}
\hline $\begin{array}{l}\text { Number of cells per ml: } \\
\text { Cell length }(\mu \mathrm{m}): \\
\text { Cell diameters }(\mu \mathrm{m}) \text { : (elliptical) }\end{array}$ & $\begin{array}{l}3.7 \times 10^{8} \\
4 \quad \pm 1 \\
0.4 \pm 0.1 \times 0.7 \pm 0.2\end{array}$ \\
\hline $\begin{array}{l}\text { Protein content per cell }(\mu \mathrm{g}): \\
\text { Bchl } b \text { content per cell (moles): }\end{array}$ & $\begin{array}{l}18.3 \\
2.25 \times 10^{-17}\end{array}$ \\
\hline $\begin{array}{l}\text { Thylakoidal stacks per cell: } \\
\text { Sacs per thylakoidal stack: } \\
\text { Mean sac diameter }(\mu \mathrm{m}) \text { : }\end{array}$ & $\begin{array}{c}7 \quad \pm 1 \\
16 \quad \pm 2 \\
0.45 \pm 0.2\end{array}$ \\
\hline $\begin{array}{l}\text { Thickness of thylakoid membranes }(\mathrm{nm}) \text { : } \\
\text { Intrathylakoidal space }(\mathrm{nm}) \text { : } \\
\text { Interthylakoidal space }(\mathrm{nm}) \text { : }\end{array}$ & $\begin{array}{ll}3 & \pm 0.3 \\
5 & \pm 1 \\
2 & \pm 0.3\end{array}$ \\
\hline $\begin{array}{l}\text { Total area of thylakoid membranes } \\
\text { per cell }\left(\mu \mathrm{m}^{2}\right) \text { : } \\
\text { Cytoplasmic membrane area } \\
\text { per cell }\left(\mu \mathrm{m}^{2}\right) \text { : }\end{array}$ & 36 \\
\hline $\begin{array}{l}\text { Number of photosynthetic complexes } \\
\text { per cell: }\end{array}$ & $2.5 \times 10^{5}-3.0 \times 10^{5}$ \\
\hline $\begin{array}{l}\text { Number of Bchl } b \text { molecules } \\
\text { per photosynthetic complex: }\end{array}$ & $\begin{array}{l}45-54^{\mathrm{a}} \\
34^{\mathrm{b}}\end{array}$ \\
\hline
\end{tabular}

a Calculated from morphometric data

b Calculated from biochemical data (Steiner 1985; Steiner and Scheer 1985)

of the envelope, however, seemed to be unusual. The crosssectioned cell wall was alternatingly electron dense and transparent (Fig. 2). When tangentionally sectioned an irregular array of electron transparent, ovoid patches (diameter $30 \mathrm{~nm}$ ) was striking (Fig. 3). Occasionally a few "thylakoid sacs" lay isolated close to disrupted cells; their typical hexagonal array of photosynthetic complexes was clearly visible. At areas of overlapping thylakoids a Moiré pattern was observed (Fig. 4, star). Structural features (arrows in Fig. 4) suggest that the thylakoidal sacs have openings. The projection area of a typical sac was about $0.2 \mu \mathrm{m}$. Frequently larger membrane sheets (up to $2 \mu \mathrm{m}$ ) were observed with a similar hexagonal distribution of photosynthetic complexes (Engelhardt et al. 1983). We therefore assume that these sheets represent large fragments of the cytoplasmic membranes which consequently should be homologous to thylakoid membranes.

The application of conventional fixation and embedding techniques on extremely halophilic organisms is rather problematic (Raymond and Sistrom 1967, 1969). Washing of the cells bears the risk of swelling and other artificial disarrangement. Even stepwise dilution of washing buffer with water leads to swelling of the cells.

Satisfactory results were obtained, however, by stepwise dehydration in parallel with reduction of the osmolarity (to prevent crystallization). Isoosmotically fixed cells differed from "osmotically stressed" preparations by intense staining of the intrathylakoidal space and by its minimal thickness (Figs. 2 and 5).

In a longitudinal section the cells of E.halochloris appeared spirillum shaped; in each bend one thylakoid stack dominated. The length of the cells was obviously correlated with the number of stacks with an average diameter of about $0.45 \mu \mathrm{m}$ (Table 1). Each stack consisted of about 16 single thylakoids adhering closely to each other. The thylakoid 

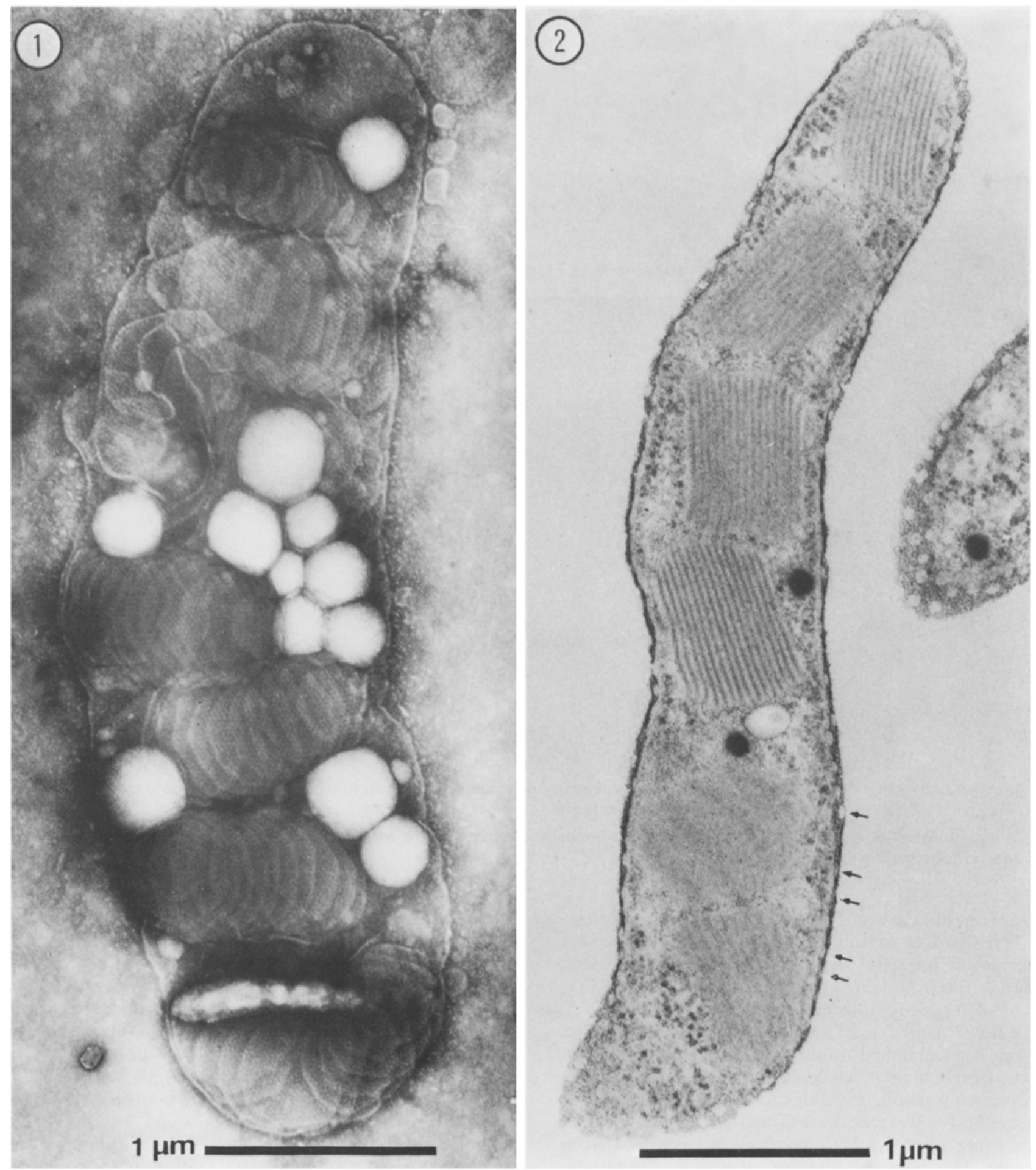

Figs. 1 and 2. Electron micrographs of cells of Ectothiorhodospira halochloris. In negatively stained preparations (Fig. 1) the cells burst during drainage and the stacks form rows of overlapping discs. The altering electron dense architecture of the cell wall is striking in longitudinal sections of Fig. 2 (see arrow)

membranes had a thickness of $3 \pm 0.3 \mathrm{~nm}$ and were separated by an interspace of $5 \pm 1 \mathrm{~nm}$. The total thickness of one stack was about $0.3 \mu \mathrm{m}$, so that one stack filled most of the cross-section area of the cell.

The thylakoid membrane appeared granulated with a periodicity of $3.6 \mathrm{~nm}$, which was more evident after photographic superposition (Figs. 6 and 7). This periodicity is interpreted as a average value of superimposed antennaantenna and antenna-reaction center complexes (about one third of the diameter of one photosynthetic complex). This is in coincidence with the structural data of the photosynthetic complexes determined from isolated, freeze dried photosynthetic membranes after high resolution shadowing (Engelhardt et al. 1983, 1985). Obviously the high degree of 

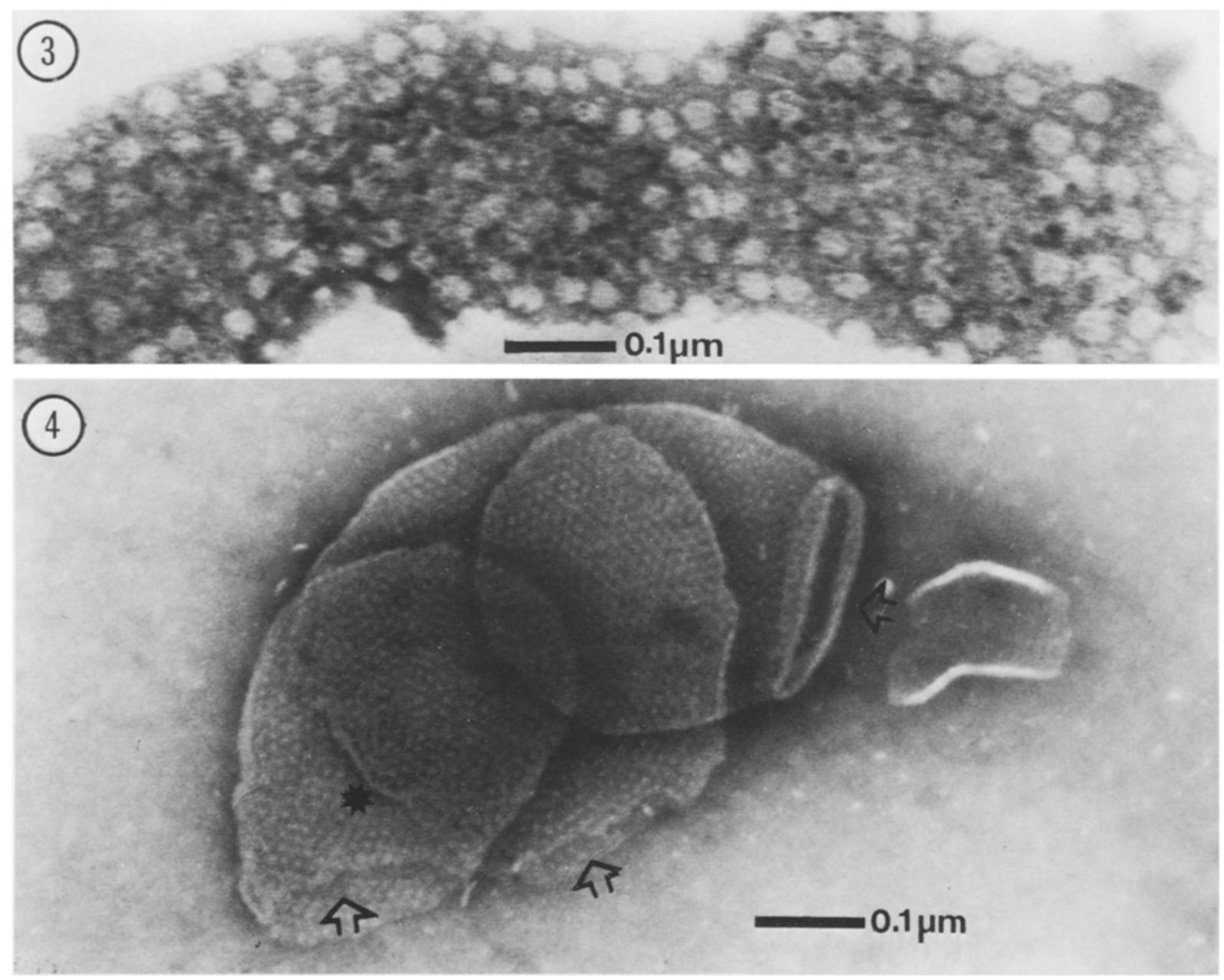

Fig. 3. Tangentional section of Ectothiorhodospira halochloris illustrating the unusual architecture of the cell wall in projection (compare to Fig. 2). The ovoid patches are irregularily ordered but similar in size (diameter about $30 \mathrm{~nm}$ )

Fig. 4. Whole thylakoidal sacs of negatively stained preparations frequently showing openings (see arrows). In regions of overlapping membranes a Moire pattern is visible (star)

order, as seen in negatively stained or freeze dried preparations, is realized as well in the living cells. Using an area of $132 \mathrm{~nm}^{2}$ of one photosynthetic complex in one living E.halochloris cell $(4.0 \mu \mathrm{m}$ long) it can be calculated that appx. 275,000 photosynthetic complexes are present.

The Bchl $b$ content is $2.25 \times 10^{-17} \mathrm{M} /$ cell (Table 1). This value has been obtained by using an improved extinction coefficient of $\mathrm{Bchl} b$, which has been determined from its anaerobic conversion to 3-devinyl-3-acetylchlorophyll $a$ (Steiner et al. 1983) (Table 2). A ratio of about 30 molecules of $\mathrm{Bchl} b$ per photosynthetic complex is calculated from these data. This is in good agreement with earlier results, where a minimum of five Bchl $b$ per one light harvesting complex were estimated from circular dichroism data (Steiner 1985). If we assume, in addition, four molecules of Bchl $b$ for the RC like in Rhodopseudomonas viridis (Deisenhofer et al. 1984) we would arrive at a sum of 34 molecules in one photosynthetic complex.

Three dimensional reconstruction of the photosynthetic apparatus of Ectothiorhodospira halochloris

It is generally accepted, that all bacterial photosynthetic membranes are formed initially by invaginations of the plasma membrane. The continuity between the two membranes persist in some bacteria, in others the photosynthetic membranes are discussed to pinch off and form vesicles (Remsen 1978). For E.halochloris no data were sofar available demonstrating the structural relation of thylakoidal stacks to the plasma membrane. In another species of the genus Ectothiorhodospira, E.mobilis (Trüper 1968), it has been proposed that the thylakoid membrane may be connected to the plasma membrane. Whether these connections are temporary or permanent is an open question (Remsen 1978).

We have applied the serial thin section technique for reconstruction of four complete stacks of the photosynthetic apparatus of E. halochloris.

The serial thin sections showed clearly, that at least $90 \%$ of the thylakoid membranes were connected with the cytoplasmic membrane (Fig. 5A-D). These membranous connections were about $50-100 \mathrm{~nm}$ wide. Thylakoids of one stack are not connected in "one row", but rather formed fan-like structures, as shown in Fig. 8. Occasionally connections to the opposite side could be observed (Fig. 8); however, multiple connections of one thylakoid membrane with the cytoplasmic membrane were never observed. From geometrical considerations of the stack structure it becomes evident, that about $10-20 \%$ of the cell cross-sections should 

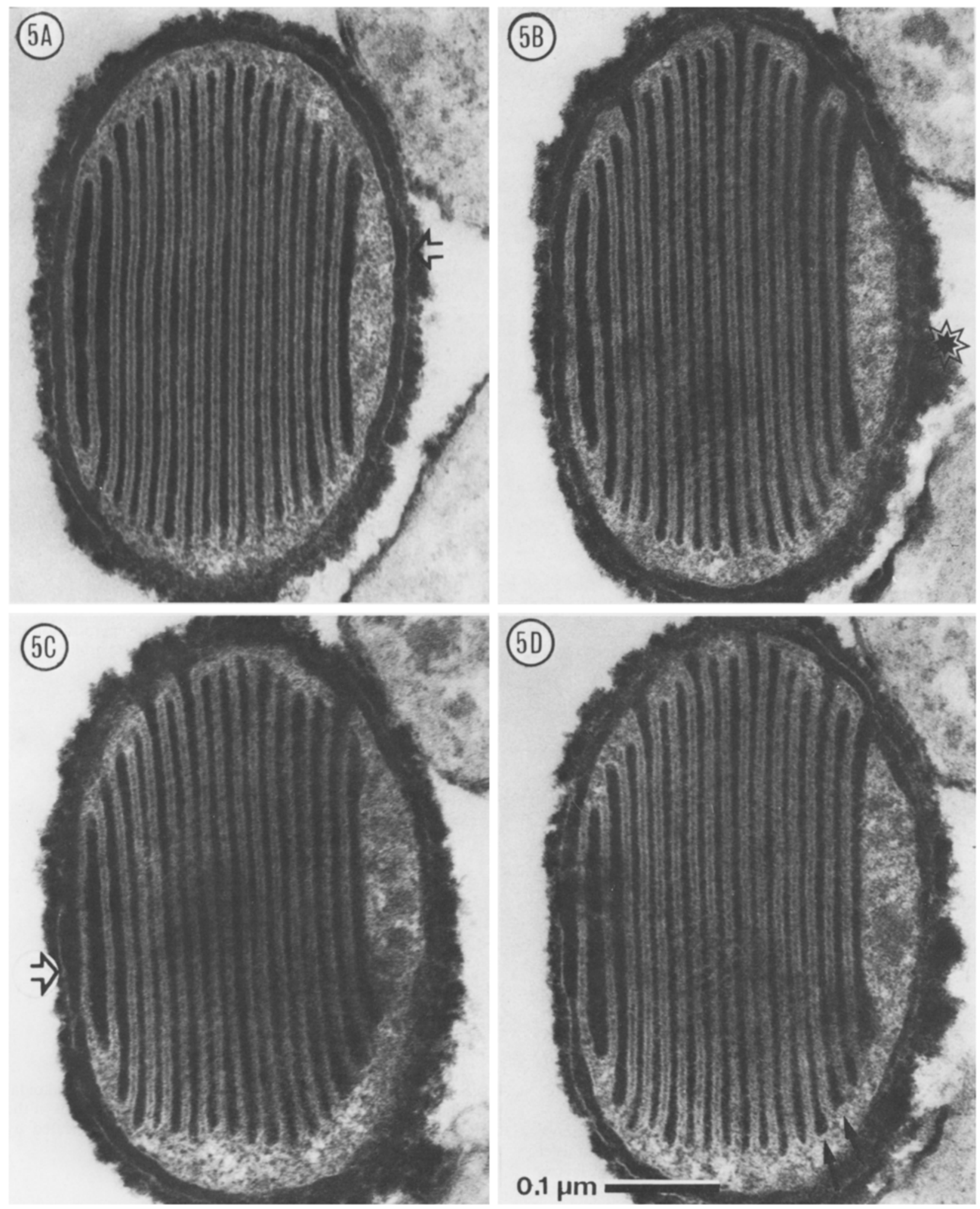

Fig. 5A-D. Serial cross-sections (section thickness: $50 \mathrm{~nm}$ ) illustrating that the thylakoidal sacs are attached to one another and are connected to the cytoplasmic membrane (A-D). The edges of the thylakoidal sacs are typically "swollen" (see arrows in D. The intrathylakoidal space is in connection to the periplasmic space. An outer membrane is clearly visible (see arrows in $\mathbf{A}$ and $\mathbf{C}$ ). Electron dense deposits (sulfur?) are typical for isoosmotically fixed cells (B, star)

show tangentionally sectioned connections, where the membrane continuity is obscured. Therefore we conclude that, in principle, all thylakoid membranes are connected to the cytoplasmic membrane.
The diameter was not constant for all the thylakoids, but showed a decrease to the upper and lower end of the stacks (Fig. 5) which is probably related to the optimal fitting of the stack into the elliptical profile of the cell cross-section. 

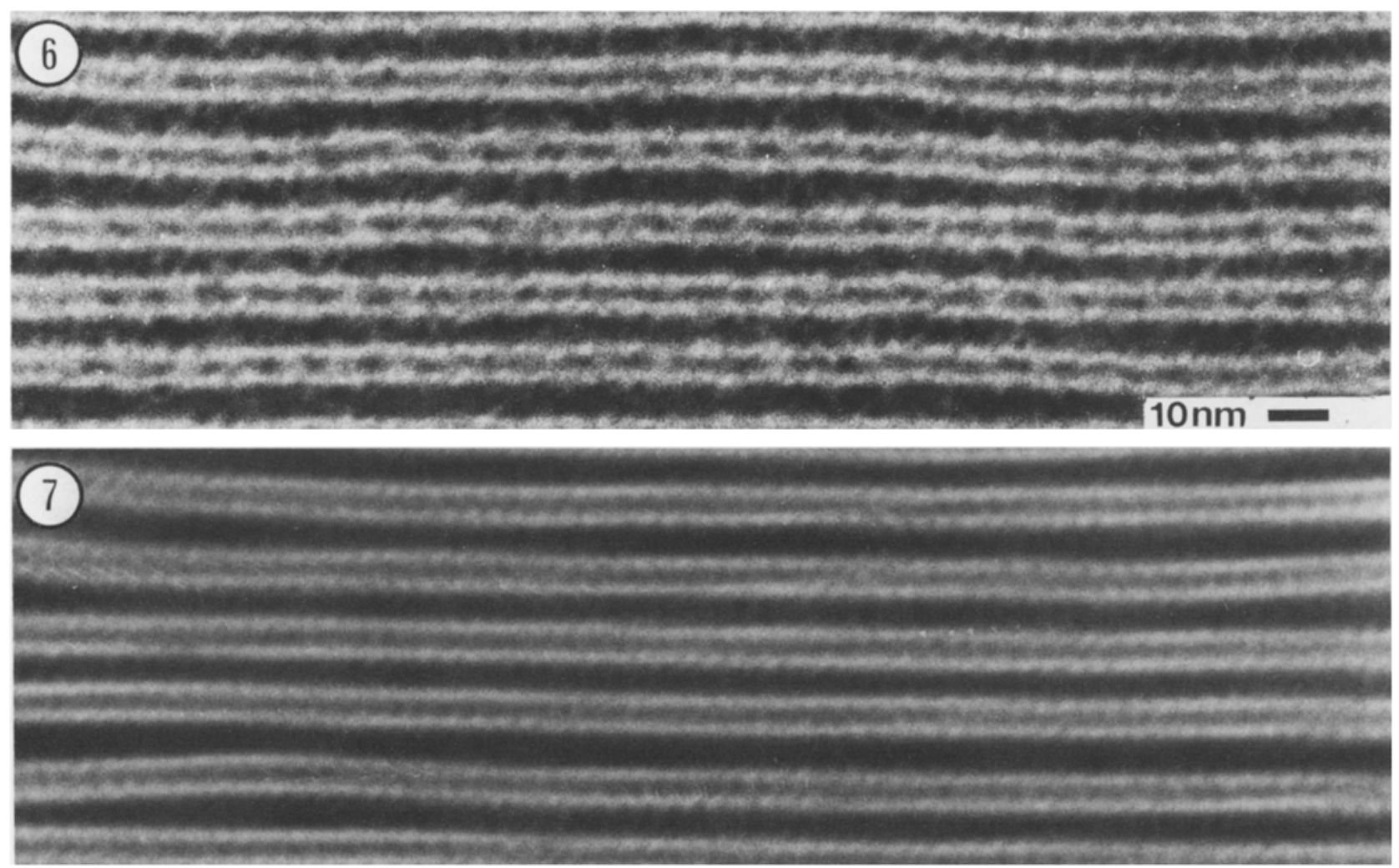

Figs. 6 and 7. High magnification of the thylakoid membranes showing periodic structures (Fig. 6). After photographic superposition the high degree of order of photosynthetic subunits is clearly visible (Fig. 7; six exposure steps - between each a random shift parallell to the thylakoids)

Table 2. Extinction coefficients

Bacteriochlorophyll $a$ (Sauer et al. 1966)

$\lambda_{\max }(\mathrm{nm})$

(in ether): $\quad \begin{array}{llll}770 & 573 & 392 & 357\end{array}$

$\varepsilon \times 10^{3}: \quad 96.0 \quad 22.0 \quad 47-1 \quad 73.4$

3-Acetyl-3-devinyl-chlorophyll $a$ (Smith and Calvin 1966)

$\lambda_{\max }(\mathrm{nm})$

$\begin{array}{llllllll}\text { (in acetone): } & 677 & 628 & 591 & 538 & 505 & 436 & 388\end{array}$

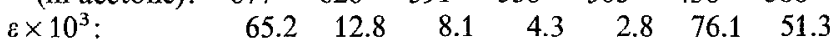

Bacteriochlorophyll $b$ (Steiner 1985)

$\lambda_{\max }(\mathrm{nm})$

(in ether): $\quad \begin{array}{lllll}794 & 676 & 578 & 408 & 368\end{array}$

$\begin{array}{llllll}\varepsilon \times 10^{3}: & 106 & 13.7 & 26.5 & 77.4 & 85.7\end{array}$

The data obtained for $\operatorname{Bchl} b$ are in fair agreement with those reported earlier $(\varepsilon 790 \mathrm{~nm}=122,000$ in acetone/methanol, Garcia et al. $1968 ; \varepsilon 1015 \mathrm{~nm}=144,000$, Clayton 1966; Clayton and Clayton 1978)

Obviously due to the membrane flexibility, the edges of the thylakoids were thicker than the inner parts (Fig. 5D, arrows), which causes the characteristic structure of the stack.

Some of the cells showed a very electron dense filling of the intrathylakoidal space (Fig. 5). This was observed

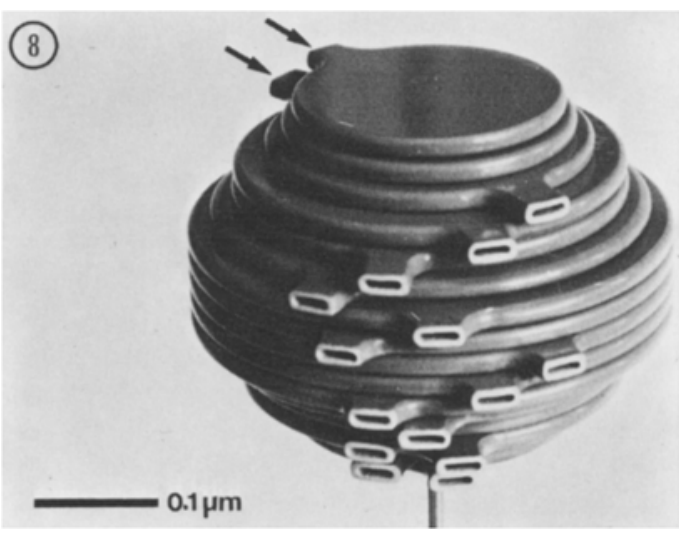

Fig. 8. Three dimensional reconstruction of a complete thylakoidal stack, based on serial electron micrographs. The connections of the thylakoidal sacs to the cytoplasmic membrane are indicated by arrows

more often with improvement of isoosmotic fixation and dehydration (see Material and methods). Therefore, we suppose that the osmiophilic filling is a characteristic feature of the living cell and washed out during conventional fixation and/or dehydration. There was no difference in staining of the intrathylakoidal space from that of the periplasmic space (Fig. 5). The continuity of the osmiophilic substance across the membranous connections proves not only a spatial connection of the intrathylakoidal space with the 
periplasmic one, but suggests in addition that they form a physiological unit.

\section{Discussion}

The high degree of biochemical similarities in purple bacteria is contrasted by wide variations in the morphology of their photosynthetic membranes (Remsen 1978). For a better understanding of photosynthesis in bacteria a complete structural analysis of the photosynthetic apparatus is necessary in addition to biochemical and physical determinations. Although there is good coincidence in the physicochemical aspects of the photosynthesis of various bacterial groups it is surprising that the structure of the photosynthetic apparatus varies widely (Remsen 1978): in Bchl $a$ containing purple bacteria the thylakoids may be arranged as densely packed lamellae (Rhodopseudomonas palustris, Cohen-Bazire and Sistrom 1966) or they may be reduced to vesicles which were proposed to be free cytoplasmic organelles (Vatter and Wolfe 1958). In the genus Ectothiorhodospira, the thylakoids are arranged as typical lamellar stacks (e.g. Remsen et al. 1968).

It is generally accepted that all of these thylakoidal structures are formed by invaginations of the cytoplasmic membrane. Although membranous continuities of thylakoid membranes with the cytoplasmic membrane are convincingly shown for E.mobilis, it is not clear, whether these continuities represent only a developmental stage or are permanent. For detailed applications of Mitchell's chemiosmotic hypothesis it is necessary to answer whether the thylakoid system is "closed" (isolated vesicles or sacs) or "open" (permanent spatial continuity of the intrathylakoidal space with the periplasmic space). Our data prove for the first time, that it is a structural principle for E.halochloris that all thylakoidal sacs are in continuity with each other and with the cytoplasmic membrane (Figs. 5 and 8). The membranous connections between sacs and the thylakoidal membrane are not strongly ordered (Fig. 8) and they can be observed at opposite sides of the cytoplasmic membrane. We therefore conclude that the initial invagination steps occur randomly. The developing thylakoids, however, are stabilized by spatial interactions when they come in contact with each other. When realizing the highly ordered three dimensional relief of the photosynthetic complexes of E. halochloris (Engelhardt et al. 1985) it is easy to imagine that two attaching thylakoid membranes fit well into one another. This is supported by detailed investigations of the membrane arrangement in R.viridis (Miller 1979, 1982; Welte and Kreutz 1982; Stark et al. 1984; Miller and Jacob 1985). Beside this steric fitting of the photosynthetic complexes, we suppose an additional physical interaction of two adjacent thylakoid membranes (hydrophobic/ hydrophilic interactions?) to keep the stack system highly ordered. (All sacs of one stack are attached to each other without any interspace; neighboring sacs have nearly the same dimensions and are almost perfectly superposed.)

A self-arrangement of complete stacks could be realized as follows: Randomly formed thylakoid membranes enlarge and are stabilized upon coming into contact with neighboring ones. Since they are in continuity with the cytoplasmic membrane, all tensions of the cell (and cytoplasmic membrane) due to movement, division, membrane enlargement and mechanical forces should directly influence the photosynthetic membranes. Giving the physical interaction between thylakoids they could in the beginning compensate tensions by sliding against each other, but are fixed to stacks when reaching maximal contact (adhesion). Maximal contact is realized for sacs of similar size and optimal orientation; this results in the typical arrangement of the stacking.

The formation of additional stacks causes a twisting of the whole cell and leads to the irregular spirilloid shape of E.halochloris which differs from the uniformly twisted structures of the Spirillaceae.

A spiral shape is realized in many different kinds of organisms; it is obviously not dependent on a common structural principle: the prokaryotic spirochaetes maintain their flexible spiriloid shape by axial filaments (axostyle); the bacteria of the genus Spirillum, however, are rigid and their shape is caused by a special architecture of their murein sacculus. In contrast, the less regular shape of E.halochloris is explained by an "inner skeleton" of thylakoidal stacks.

The complete intrathylakoidal space of one cell is continuous and located "outside" the cytoplasmic membrane ("periplasmic space"). An additional membrane ("outer membrane") obviously is necessary to define this "periplasmic space" and separate it from both the cytoplasm and the environment. This outer membrane should therefore play an important role in transport phenomena.

\section{References}

Clayton RK (1966) Spectroscopic analysis of bacteriochlorophylls in vitro and in vivo. Photochem Photobiol 5:669-677

Clayton RK, Clayton BJ (1978) Molar extinction coefficients and other properties of an improved reaction center preparation from Rhodopseudomonas viridis. Biochim Biophys Acta 501: $478-487$

Cohen-Bazire G, Sistrom WR (1966) The procaryotic photosynthetic apparatus. In: Vernon LP, Seely GR (eds) The chlorophylls. Academic Press, Inc, New York, pp 313-341

Deisenhofer J, Epp O, Miki K, Huber R, Michel H (1984) X-ray structure analysis of a membrane protein complex. Electron density map at $3 \mathrm{~A}$ resolution and a model of the chromophores of the photosynthetic reaction center from Rhodopseudomonas viridis. J Mol Biol 180:385-398

Drews G, Giesbrecht P (1966) Rhodopseudomonas viridis, nov. spec, ein neu isoliertes, obligat phototrophes Bacterium. Arch Mikrobiol 53:255-262

Eimhjellen KE, Aasmundrud O, Jensen A (1963) A new bacterial chlorophyll. Biochem Biophys Res Comm 10:232-236

Eimhjellen KE, Steensland H, Traetteberg I (1967) A Thiococcus spec. nov. gen. its pigments and internal membrane. Arch Mikrobiol 59:82-92

Eimhjellen KE (1970) Thiocapsa pfennigii sp. nov., a new species of phototrophic sulfur bacteria. Arch Mikrobiol 73:193-194

Engelhardt H, Baumeister W, Saxton WO (1983) Electron microscopy of photosynthetic membranes containing bacteriochlorophyll b. Arch Microbiol 135:169-175

Engelhardt H, Guckenberger R, Hegerl R, Baumeister W (1985) High resolution shadowing of freeze-dried bacterial photosynthetic membranes: multivariate statistical analysis and surface relief reconstruction. U1tramicroscopy $16: 395-\ldots 10$

Formanek H (1979) Preparation of hydrophilic, single crystalline specimen supports of Graphiteoxide. Ultramicroscopy 4:227232

Garcia A, Vernon LP, Ke B, Mollenhauer H (1968) Some structural and photochemical properties of Rhodopseudomonas NHTC 133 subchromatophore particles obtained by treatment with Triton $X-100$. Biochem 7:326-332

Gottstein J (1984) Untersuchungen zum Einfluß von Tensiden auf die Photosynthese Membran und isolierte Reaktionszentren 
von Rhodospirillum rubrum und auf isolierte Bakteriochlorophylle. Diplomarbeit, Univ München

Imhoff JF, Trüper HG (1977) Ectothiorhodospira halochloris sp. nov., a new extremely halophilic phototrophic bacterium containing bacteriochlorophyll b. Arch Microbiol 114:115-121

Imhoff JF, Trüper HG (1981) Ectothiorhodospira abdelmalekii sp. nov., a new halophilic and alkaliphilic phototrophic bacterium. Zbl Bakt Hyg, I. Abt Orig C2:228-234

Miller KR (1979) The photosynthetic membrane. Sci Amer 241:100-111

Miller KR (1982) Three-dimensional structure of a photosynthetic membrane. Nature 300:53-55

Miller KR, Jacob JS (1985) Rhodopseudomonas viridis photosynthetic membrane: arrangement in situ. Arch Microbiol 142:333-339

Neutzling O, Trüper HG (1982) Assimilatory sulfur metabolism in Rhodopseudomonas sulfoviridis. Arch Microbiol 133:145-148

Raymond JC, Sistrom WR (1967) The isolation and preliminary characterization of a halophilic photosynthetic bacterium. Arch Mikrobiol 59:255-268

Raymond JC, Sistrom WR (1969) Ectothiorhodospira halophila: a new species of the genus Ectothiorhodospira. Arch Mikrobiol 69:121- 126

Remsen CC (1978) Comparative subcellular architecture of photosynthetic bacteria. In: Clayton RK, Sistrom WR (eds) The photosynthetic bacteria. Plenum Press, New York, pp 31 60

Remsen CC, Watson SW, Waterbury JB, Trüper HG (1968) Fine structure of Ectothiorhodospira mobilis Pelsh. J Bacteriol $95: 2374-2392$

Sauer K, Smith JRL, Schultz AJ (1966) The dimerization of chlorophyll a, chlorophyll $b$ and bacteriochlorophyll in solution. J Am Chem Soc 88:2681-2688
Smith JRL, Calvin M (1966) Studies on the chemical and photochemical oxidation of bacteriochlorophyll. J Am Chem Soc 88:4500-4506

Spurr AR (1969) A low viscosity epoxy resin embedding medium for electron microscopy. J Ultrastruct Res 26:31-43

Stark W, Kühlbrandt W, Wildhaber I, Wehrli E, Mühlethaler K (1984) The structure of the photoreceptor unit Rhodopseudomonas viridis. $\mathrm{EMBO} \mathrm{J} 3: 777-783$

Steiner R, Cmiel E, Scheer H (1983) Chemistry of bacteriochlorophyll $\mathrm{b}$ : identification of some (photo) oxidation products. Z Naturforsch $38 \mathrm{c}: 748-752$

Steiner $R$ (1985) In vivo und in vitro-Untersuchungen an den Bakteriochlorophyll b-haltigen Organismen Ectothiorhodospira halochloris, Ectothiorhodospira abdelmalekii und Rhodopseudomonas viridis. Diss Univ München

Steiner R, Scheer H (1985) Characterisation of a B800/1020 antenna from the photosynthetic bacteria Ectothiorhodospira halochloris and Ectothiorhodospira abdelmalekii. Biochim Biophys Acta $807: 278-284$

Strain HH, Svec WA (1966) Extraction, separation, estimation and isolation of the chlorophylls. In: Vernon LP, Seely GR (eds) The chlorophylls. Academic Press, New York

Trüper HG (1968) Ectothiorhodospira mobilis Pelsh, a photosynthetic sulfur bacterium depositing sulfur outside the cells. J Bacteriol 95:1910-1920

Vatter AE, Wolfe RS (1958) The structure of photosynthetic bacteria. J Bacteriol 75:480-488

Welte W, Kreutz W (1982) Formation, structure and composition of a planar hexagonal lattice composed of specific protein-lipid complexes in the thylakoid membranes of Rhodopseudomonas viridis. Biochim Biophys Acta 692:479-488

Received April 1, 1986/Accepted September 2, 1986 